\title{
Elevated Tenascin-C Serum Levels in Patients With Axial Spondyloarthritis
}

\author{
Kristýna BUBOVÁ ${ }^{\mathbf{1}}$, Klára PRAJZLEROVÁ ${ }^{\mathbf{1}}$, Hana HULEJOVÁ ${ }^{\mathbf{1}}$, Monika GREGOVÁ ${ }^{\mathbf{1}}$, \\ Kateřina MINTÁLOVÁ ${ }^{1}$, Markéta HUŠÁKOVÁ ${ }^{1}$, Šárka FOREJTOVÁ ${ }^{1}$, Mária \\ FILKOVÁ ${ }^{1}$, Michal TOMČÍK ${ }^{1}$, Jiří VENCOVSKÝ ${ }^{1}$, Karel PAVELKA ${ }^{1}$, Ladislav ŠENOLT ${ }^{1}$ \\ ${ }^{1}$ Department of Rheumatology, First Faculty of Medicine, Charles University and Rheumatology \\ Institute, Prague, Czech Republic
}

Received December 4, 2019

Accepted April 22, 2020

Epub Ahead of Print June 25, 2020

\section{Summary}

This study aimed to examine serum tenascin C (TNC) in different subsets of axial spondyloarthritis (axSpA) patients. Sixty-one patients fulfilling the Assessment of SpondyloArthritis international Society classification criteria for axSpA and 20 healthy subjects (HS) were included in study. Based on imaging, patients were classified as non-radiographic $(n=16)$ and radiographic $(n=45)$ axSpA. TNC serum levels were determined by ELISA. Disease-related factors including the Bath Ankylosing Spondylitis Disease Activity Index (BASDAI) and C-reactive protein (CRP) levels were determined. TNC levels were elevated in axSpA patients [535.3 (457.7-677.2) $\mathrm{ng} / \mathrm{ml}$ ] compared to HS [432.1 (329.1-565.9) ng/ml, $\mathrm{p}=0.007]$. Dividing axSpA into radiographic and non-radiographic subsets, the difference in TNC was observed between the radiographic subset and HS [535.3 (434.5-677.2) vs. 432.1 (329.1-565.9) ng/ml, p=0.022]. TNC levels did not correlate with disease activity measures (serum CRP or BASDAI). Nevertheless, the weak correlation of TNC levels with different disease stages $(r=0.25, p=0.025)$ was found, with the highest levels in patients with syndesmophytes. TNC levels are elevated across various subsets of axSpA, and although not related to systemic disease activity, TNC levels might reflect chronic structural spinal changes in axSpA patients. However, its specific role in bone metabolism should be elucidated in further studies.

\section{Key words}

Axial spondyloarthritis - Ankylosing spondylitis - Tenascin C • Disease activity $\bullet$ Syndesmophytes

\section{Corresponding author}

Ladislav Šenolt, Institute of Rheumatology, Na Slupi 4, 12850 Prague 2, Czech Republic. E-mail: senolt@revma.cz

\section{Introduction}

Spondyloarthritis (SpA) is a common chronic inflammatory rheumatic disease affecting axial skeleton as well as peripheral joints. According to prevailing features, the whole group can be divided into predominantly axial and predominantly peripheral diseases. The prototype of the axial spondyloarthritis ( $\operatorname{axSpA})$ is the radiographic form of the disease known as ankylosing spondylitis, with a prevalence of $0.32-1.4 \%$ in the general population (Sieper and Poddubnyy 2017). The long-term course of the disease is associated with both bone erosion and new bone formation, which can gradually lead to ankylosis of the affected joints. Recent progress in the field of radiology allows detection of early inflammatory changes characterized as bone marrow edema on sacroiliac joints (SIJ) and spine vertebras using magnetic resonance imaging (MRI). Thus, patients who do not fulfil the modified New York criteria for radiographic axSpA (van der Linden, Valkenburg, and Cats 1984) while missing the radiological criteria, however, develop typical bone marrow edema on MRI and can be classified according to the new Assessment of SpondyloArthritis international Society (ASAS) classification criteria (Rudwaleit, Braun, Sieper and Assessment of SpondyloArthritis international 2009) as

PHYSIOLOGICAL RESEARCH • ISSN 1802-9973 (online) 
non-radiographic axSpA. Despite the new possibilities for detection of early disease, the delay from the occurrence of the first symptoms to the diagnosis is still striking (Dincer et al. 2008, Forejtova et al. 2008, Sorensen and Hetland 2015).

Recent studies have focused on the role of soluble biomarkers that could serve as a disease activity measure or surrogate diagnostic/prognostic biomarkers (Maksymowych 2017, Prajzlerova et al. 2016). The only widely used biomarkers for mentioned purposes are HLA-B27 antigen (contributing to the disease diagnosis) and C-reactive protein (CRP) (reflecting inflammatory processes). However, these lacks sufficient sensitivity and specificity for axSpA detection (Deodhar 1989, Poddubnyy et al. 2010, Spoorenberg et al. 1999). Other potential biomarkers have been recently studied, but none have demonstrated associations sufficient to justify clinical use (Maksymowych 2017).

Tenascin-C (TNC) is a large pro-inflammatory extracellular matrix glycoprotein that consists of N-terminal TNC assembly domain, 14.5 epidermal grow factor-like repeats, fibronectin type III repeat domains, and the $\mathrm{C}$ - terminal fibrinogen-like globular domain (Midwood et al. 2016). TNC is expressed by myeloid cells in response to pathogen-associated molecular patterns (PAMPs), mechanical strain, reactive oxygen species, cytokines, and growth factors. Thus, it is believed to reflect tissue injury during the inflammatory process and also active tissue remodeling (Midwood and Orend 2009). TNC expression is typically transient, and its levels are repressed as soon as the inflammation and tissue repair are completed. Contrary to physiologic functions, persistently elevated expression of TNC was observed in several immune-mediated rheumatic diseases, such as rheumatoid arthritis (RA), systemic lupus erythematosus (SLE), and psoriatic arthritis (PsA) (Midwood and Orend 2009, Page et al. 2012, Udalova et al. 2011).

Also, elevated serum TNC levels were described in patients with radiographic axSpA compared to healthy subjects, and TNC levels correlated with laboratory and clinical measures of disease activity (Gupta et al. 2018, Page et al. 2012). The aim of our study was to study the levels of TNC in radiographic as well as nonradiographic axSpA patients, and to elucidate its potential association with disease severity.

\section{Methods}

\section{Patients}

Sixty-one patients who fulfilled the Assessment of SpondyloArthritis international Society (ASAS) classification criteria for axSpA were included in this study (Rudwaleit et al. 2009). Based on imaging findings, patients were further classified as non-radiographic $\operatorname{axSpA}(n r-a x S p A)(n=16)$ and as radiographic axSpA $(n=45)$. Patients with radiographic axSpA were further divided into two subgroups on the patients with pure SIJ changes (subgroup I, $n=22$ ) and on the patients with SIJ changes together with spinal syndesmophytes (subgroup II, $n=23$ ) based on radiographic findings.

The following data were collected: clinical and laboratory disease activity measures, demographic status, disease-related factors [such as the Bath Ankylosing Spondylitis Disease Activity Index (BASDAI)(Jones, Calin, \& Steiner, 1996) and CRP levels], current medications [non-steroidal anti-inflammatory drugs (NSAIDs), conventional synthetic disease-modifying anti-rheumatic drugs (csDMARDs), and biological treatments (bDMARDs)], age, gender, body mass index (BMI), initial symptoms (e.g., back pain, peripheral arthritis, extra-articular manifestations), age at diagnosis, occurrence of peripheral arthritis and extra-articular manifestations, and the presence of HLA-B27 antigen. Twenty age- and sex-matched healthy subjects were enrolled in the study. Healthy subjects were not treated for any autoimmune or rheumatic disease. The local ethics committee of the Institute of Rheumatology in Prague approved this study. Written informed consent was obtained from all individuals before initiation of the study.

\section{Imaging}

Radiographs of the SIJ, lumbar, thoracic, and cervical spine were obtained from all patients before blood withdrawal. A trained rheumatologist and a central radiologist scored the radiographs for the initial disease classification, both were blinded to all clinical data. Cervical and lumbar spine radiographs were scored according to the modified Stoke Ankylosing Spondylitis Spine Score (mSASSS) by a trained rheumatologist. MRI images were obtained before recruitment and were read by a trained rheumatologist who was blinded to all clinical data.

Patients were classified as radiographic axSpA according to the New York classification criteria and as 
nr-axSpA fulfilling imaging arm of the ASAS classification criteria for $\mathrm{axSpA}$, if the radiographic findings of the SIJ did not achieve required radiographic stage and the MRI was positive (i.e., characteristic bone marrow oedema highly suggestive for presence of sacroiliitis) with at least one feature of SpA (Rudwaleit et al. 2009).

\section{Laboratory analysis}

Fasting blood samples were collected from all individuals and immediately centrifuged. The serum samples were stored at $-80{ }^{\circ} \mathrm{C}$ until analysis. Serum TNC levels were determined using the human TNC Large (FN III-B) Assay ELISA kit from IBL (Fujioka, Japan).
Samples were diluted 400-fold. The intra and inter-assay coefficients of variation for this ELISA are $6.4 \%$ $(5.43 \mathrm{ng} / \mathrm{ml})$ and $3.5 \%(5.55 \mathrm{ng} / \mathrm{ml})$ respectively. The sensitivity for this kit was $44 \mathrm{pg} / \mathrm{ml}$. The absorbance was measured by ELISA reader (SUNRISE, Tecan, Salzburg, Austria) using $450 \mathrm{~nm}$ as the primary wavelength. Serum CRP levels were determined by an immuno-turbidimetric technique using an Olympus AU 400 biochemical analyser (Olympus Optical, Tokyo, Japan). HLA-B27 was detected by flow cytometry using an IOTest HLA-B27-FITC/HLA-B7-PE (Beckman Coulter Immunotech SAS, Marseille, France) and a $\mathrm{BD}^{\mathrm{TM}}$ HLAB27 Kit (BD Bioscience, San Jose, CA, USA).

Table 1. Baseline characteristics: demographic and clinical features

\begin{tabular}{|c|c|c|c|c|}
\hline Characteristics & $\begin{array}{c}\operatorname{AxSpA} \\
(n=61)\end{array}$ & $\begin{array}{c}\text { Nr-axSpA } \\
\quad(n=16)\end{array}$ & $\begin{array}{c}\text { AS } \\
(n=45)\end{array}$ & $\begin{array}{c}\text { HC } \\
(n=20)\end{array}$ \\
\hline Sex: male, $n(\%)$ & $44(72.1)$ & $6(37.5)$ & $38(84.4)$ & $15(75)$ \\
\hline Age (years), mean $( \pm S D)$ & $37.8(13.3)$ & $37.1(11.0)$ & $37.5(14.2)$ & $37.3(10.8)$ \\
\hline$B M I\left(\mathrm{~kg} / \mathrm{m}^{2}\right)$, mean $( \pm S D)$ & $26.0(4.0)$ & $24.2(3.9)$ & $26.6(3.9)$ & - \\
\hline$H L A-B 27, n(\%)$ & $57(93.4)$ & $15(93.8)$ & $42(93.3)$ & - \\
\hline Disease duration (years), median (IQR) & $4.0(0.6-8.0)$ & $0.2(0.0-3.0)$ & $5.0(2.0-8.0)$ & - \\
\hline$B A S D A I$, median $(I Q R)$ & $5.2(2.6-7.4)$ & $4.8(1.4-6.6)$ & $5.5(3.4-7.6)$ & - \\
\hline CRP (mg/l), median (IQR) & $9.7(3.7-16.2)$ & $4.0(1.2-10.8)$ & $11.1(5.4-20.0)$ & - \\
\hline Peripheral arthritis, $n(\%)$ & $30(49.2)$ & $12(75.0)$ & $18(40.0)$ & - \\
\hline Hip involvement, $n(\%)$ & $16(26.2)$ & $3(18.8)$ & $13(28.9)$ & - \\
\hline Enthesitis/Tendynitis, $n(\%)$ & $19(31.1)$ & $9(56.3)$ & $10(22.2)$ & - \\
\hline \multicolumn{5}{|l|}{ Extraarticular manifestations: } \\
\hline$I B D, n(\%)$ & $1(1.6)$ & $1(6.3)$ & $0(0.0)$ & - \\
\hline Daktylitis, $n(\%)$ & $2(3.3)$ & $2(12.5)$ & $0(0.0)$ & - \\
\hline Psoriasis, $n(\%)$ & $4(6.6)$ & $0(0.0)$ & $4(8.9)$ & - \\
\hline Uveitis, $n(\%)$ & $21(34.4)$ & $6(37.5)$ & $15(33.3)$ & - \\
\hline \multicolumn{5}{|l|}{ First symptoms: } \\
\hline Back pain, $n(\%)$ & $36(59.0)$ & $8(50.0)$ & $28(62.2)$ & - \\
\hline Uveitis, $n(\%)$ & $5(8.2)$ & $0(0.0)$ & $5(11.1)$ & - \\
\hline Peripheral Arthritis, $n(\%)$ & $8(13.1)$ & $4(25.0)$ & $4(8.9)$ & - \\
\hline Other, $n(\%)$ & $12(19.7)$ & $4(25.0)$ & $8(17.8)$ & - \\
\hline \multicolumn{5}{|l|}{ Treatment: } \\
\hline$N S A, n(\%)$ & $37(60.7)$ & $10(62.5)$ & $27(60.0)$ & - \\
\hline$c s D M A R D s, n(\%)$ & $10(16.4)$ & $5(31.3)$ & $5(11.1)$ & - \\
\hline bDMARDs, $n(\%)$ & $15(24.6)$ & $1(6.3)$ & $14(31.1)$ & - \\
\hline$T N C(n g / m l)$, median $(I Q R)$ & $\begin{array}{c}535.3 \\
(457.7-677.2)\end{array}$ & $\begin{array}{c}511.1 \\
(416.7-700.9)\end{array}$ & $\begin{array}{c}535.3 \\
(434.5-677.2)\end{array}$ & $\begin{array}{c}432.1 \\
(329.1-565.9)\end{array}$ \\
\hline
\end{tabular}

AS, ankylosing spondylitis, axSpA, axial spondyloarthritis, BASDAI, Bath Ankylosing Spondylitis Disease Activity Index, BMI, body mass index, bDMARDs, biological disease-modifying anti-rheumatic drugs, CRP, C-reactive protein, cSDMARDs, conventional synthetic disease-modifying anti-rheumatic drugs, n, number, NSAIDs, non-steroidal anti-inflammatory drugs, IBD, inflammatory bowel disease, $\mathrm{IQR}$, interquartile range, $\mathrm{nr}-\mathrm{axSpA}$, non-radiographic axial spondyloarthritis 


\section{Statistical analysis}

The data are presented as the median [interquartile range (IQR)] if not stated otherwise. Statistical analyses were performed using GraphPad Prism 5.1 (GraphPad Software, San Diego, CA, USA). The Kolmogorov-Smirnov test of normality was used for all the variables. Spearman's correlation coefficients were calculated to determine the association between TNC levels and the other variables. For comparison between the groups, the Mann-Whitney U test and Kruskal-Wallis test were used. Fisher's exact test was performed for the comparison of categorical variables. P-values less than 0.05 were considered statistically significant.

\section{Results}

Demographic and clinical characteristics of patients with $\operatorname{axSpA}$

All demographic and clinical characteristics of axSpA patients and healthy subjects are summarized in Table 1. The majority of axSpA patients were men (72\%), the mean age was $38.0( \pm 13 \mathrm{SD})$ years, and duration from disease diagnosis was $4.0(0.6-8.0)$ years. The majority of patients were HLA-B27 positive $(93.4 \%)$. More than half of the patients were treated with NSAIDs regularly, and a small part of the patients was treated with csDMARDs for concurrent peripheral arthritis, and quarter of the patients was treated with bDMARDs. The median serum CRP level was $9.7(3.7-16.2) \mathrm{mg} / \mathrm{l}$ and BASDAI was $5.2(2.6-7.4)$. Less than half of the patients had extraarticular manifestations before recruitment. Twenty healthy subjects ( $75 \%$ males) with a mean age $37.3( \pm 10.8 \mathrm{SD})$ years were included.

Demographic and clinical differences between axSpA subsets

As recently demonstrated by our larger study (Bubova et al., 2019), significant differences between non-radiographic and radiographic subsets of the disease were found in sex distribution, male gender was more frequent in patients with radiographic compared to those with a non-radiographic subset $(84.4 \%$ vs $37.5 \%$ respectively, $\mathrm{p}<0.001)$. Furthermore, we found significant difference in sex distribution between non-radigraphic subset and $\mathrm{HC}(\mathrm{p}=0.04)$. Secondly, as anticipated, patients with radiographic axSpA had longer disease duration compared to nr-axSpA patients [5.0 (2.0-8.0) vs. $0.2(0.0-3.0)$ years respectively, $\mathrm{p}<0.001]$. Nr-axSpA patients developed peripheral arthritis more frequently compared to radiographic axSpA patients $(75.0 \%$ vs. $40.0 \%$ respectively, $\mathrm{p}=0.021$ ). BASDAI was comparable between both groups [4.8 (1.4-6.6) for nr-axSpA and 5.5 (3.4-7.6) for radiographic axSpA, $\mathrm{p}=0.10]$. However, serum CRP levels were significantly higher in radiographic compared to non-radiographic subset [11.1 (5.4-20.0) vs. $4.0(1.2-10.8) \mathrm{mg} / \mathrm{l}$ respectively, $\mathrm{p}=0.006]$. The rest of the demographic and clinical features remained comparable between both groups (Table 1).

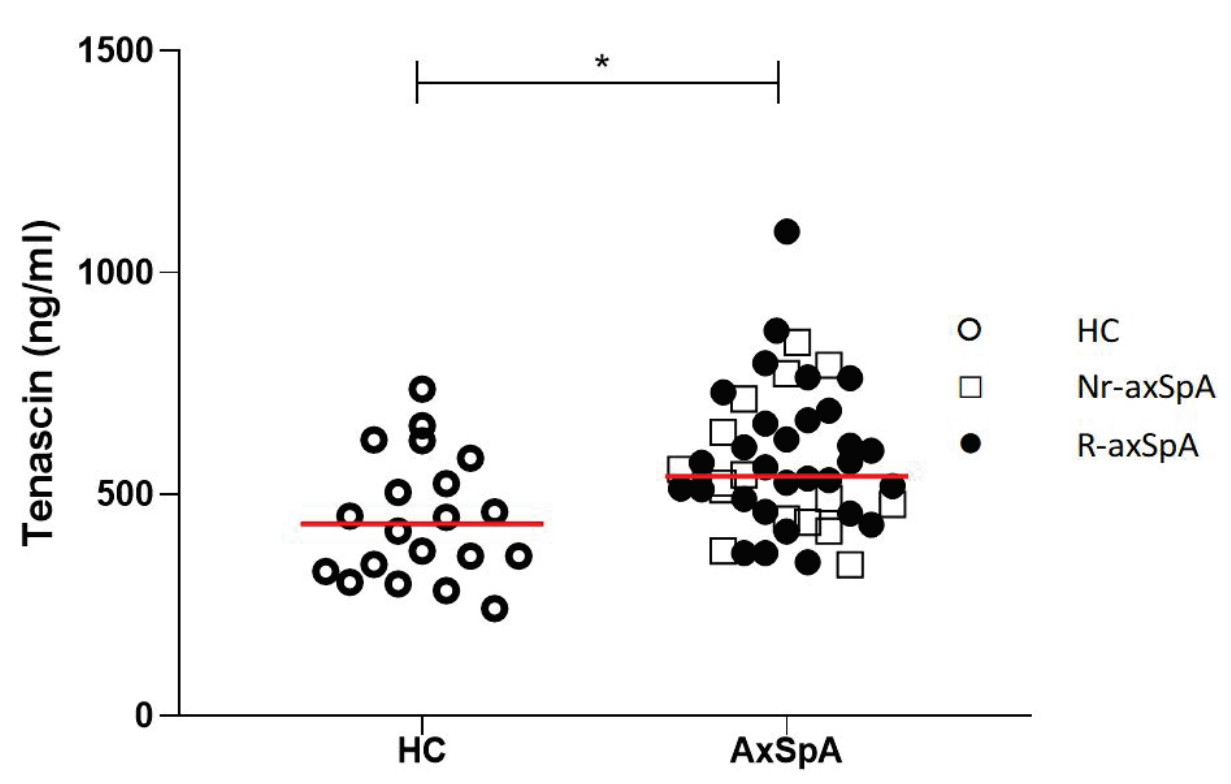

Fig. 1. Tenascin $C$ levels in axial spondyloarthritis (axSpA) as compared with healthy controls (HC) (median), $\mathrm{p}=0.007$. 


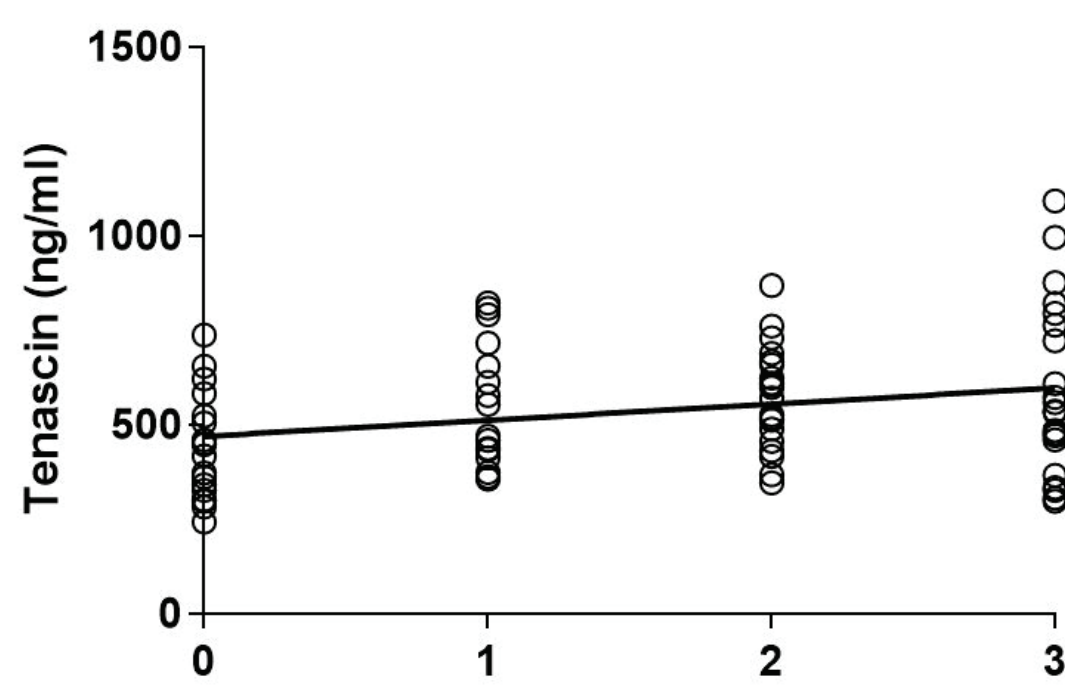

Fig. 2. Correlation among serum tenascin C levels and disease radiographic stages ( $\mathbf{0}$ : healthy controls,

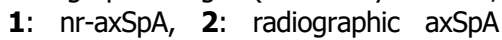
without syndesmophytes, 3: radiographic axSpA with syndesmophytes). Spearman $r=0.25, p=0.02$.
Serum TNC levels are elevated in patients with axSpA and presence of syndesmophytes

TNC levels were higher in axSpA patients compared to healthy subjects [535.3 (457.7-677.2) vs. 432.1 (329.1-565.9) ng/ml), p=0.007 (Fig. 1)]. Dividing $\operatorname{axSpA}$ patients into non-radiographic and radiographic subsets and comparing them to healthy subjects by the Kruskal-Wallis test was significant [511.1 (416.7-700.9), 535.3 (4 34.5-677.2) vs. 432.1 (329.1-565.9) ng/ml respectively, $\mathrm{p}=0.02$ ], however, when Dunn's Multiple Comparison test was applied, TNC levels were significantly higher only in radiographic axSpA compared to healthy subjects $(p=0.02)$. Although we found a weak correlation between serum TNC levels and disease radiographic stages $(r=0.25, p=0.02$, Fig. 2$)$, we could not confirm the significant correlation between TNC levels and mSASSS $(\mathrm{r}=0.12, \mathrm{p}=0.42)$.

Serum TNC levels, disease activity, and extraarticular manifestations

TNC serum levels did not correlate with CRP serum levels in patients with $\operatorname{axSpA}(\mathrm{r}=0.24, \mathrm{p}=0.07)$, neither in both subsets separately. Although CRP serum levels were significantly higher in $\mathrm{r}-\mathrm{axSpA}$, the TNC serum levels were comparable in both axSpA subsets. In agreement, TNC serum levels did not correlate with BASDAI values in all axSpA patients nor in either of the subsets $(\mathrm{p}=0.88$ for $\operatorname{axSpA}, \mathrm{p}=0.48$ for $\mathrm{nr}-\mathrm{axSpA}, \mathrm{p}=0.37$ for radiographic axSpA).

We did not find any significant differences in TNC serum levels between axSpA patients with peripheral arthritis and those with purely axial disease. Similar results were observed for extraarticular manifestations and the presence of HLA-B27 antigen.
TNC serum levels did not differ between patients on NSAIDs and those on csDMARDs/bDMARDs [512.0 (413.3-638.9] vs. 590 (479.0-762.5), respectively, $\mathrm{p}=0.07]$.

\section{Discussion}

We found that serum TNC levels are significantly higher in patients with axSpA, particularly in those with radiographic signs of advanced disease, compared to healthy subjects. To our knowledge, this is the first study to examine serum levels of TNC among different axSpA subsets. The levels of serum TNC were comparable among axSpA patients, despite the difference in disease activity measured by CRP levels which were lower in non-radiographic compared to radiographic subsets of the disease.

In line with our findings, TNC levels have been recently demonstrated to be higher in patients with radiographic axSpA (Gupta et al. 2018), but also with other immune-mediated rheumatic diseases, such as rheumatoid arthritis, psoriatic arthritis, juvenile idiopathic arthritis, inflammatory myopathies, or systemic lupus erythematosus (Hasegawa et al. 2007, Page et al. 2012, Shukla et al. 2015, Závada et al. 2015), compared to healthy subjects. TNC levels were also found to be elevated in some non-rheumatologic diseases, such as myocardial infarction, chronic hepatitis $\mathrm{C}$, melanoma, ovarian cancer, ulcerative colitis, and a variety of other diseases (Amonkar et al. 2009, Sato et al. 2006, Shao et al. 2015, Tanaka et al. 2006). Taking these data into account, we propose that systemic TNC elevation is unspecific and presumably related to tissue damage and the activation of immune as well as resident tissue cells. 
TNC levels did not correlate with disease activity assessed by BASDAI in our study, which is in agreement with Gupta et al. (2018) and which could be explained by the higher level of patient subjective perception reflected in this index. The authors, however, observed significant correlation between TNC levels and systemic measures of disease activity, such as ESR and CRP, but also a more specific disease activity index [Ankylosing Spondylitis Disease Activity Score (ASDAS)]. Unfortunately, ASDAS was not performed in our study, but we could find a trend towards correlation between TNC and CRP serum levels, which might support a potential relation between TNC and immune-mediated disease activity. We observed that neither the presence of peripheral arthritis nor anterior uveitis altered the levels of serum TNC in our study. Although serum TNC levels did not correlate with disease activity (DAS28) in patients with RA, TNC levels were higher and correlated with systemic measures of disease activity in children with enthesitis-related arthritis, a subtype of juvenile idiopathic arthritis (Shukla, et al., 2015). Furthermore, we have recently demonstrated that TNC is associated with disease activity and might predict flare of the disease in patients with SLE (Závada et al. 2015).

In previous studies, TNC showed correlations with joint damage in some rheumatic conditions (e.g., although it did not correlate with disease activity, TNC serum levels correlated positively with ultrasound determined erosion scores in patients with RA), (Page et al. 2012). TNC synovial fluid levels significantly correlated with radiographic grading in patients with knee OA (Hasegawa et al. 2004). In line with these data, in our study, serum TNC levels were increased in axSpA patients, particularly in those with advanced disease. There is evidence that, on the molecular level, TNC can promote the increased synthesis of pro-inflammatory mediators associated with axSpA pathogenesis, TNF and IL-17 (Midwood et al. 2009, Ruhmann et al. 2012). Also, intraarticular instillation of TNC in an arthritis animal model induced synovial inflammation, contrary to TNC deficient mice that show rapid resolution of joint inflammation and reduced disease severity (Midwood et al. 2009).

TNC levels did not significantly differ between radiographic and non-radiographic subsets of the disease, which could be explained by the activation of the immune system already at early phases of the disease. However, the major limitation of our study is the relatively small number of patients, particularly those with non-radiographic subset, and the fact we had only baseline data with no further follow up. To prove whether $\mathrm{TNC}$ could be an indicator of bone changes in $\mathrm{axSpA}$, larger studies with longitudinal design are necessary.

To conclude, serum TNC levels are higher in patients across various subsets of axSpA, and although not associated with disease activity, it can reflect radiographic signs of advanced disease. Therefore, TNC is a candidate biomarker for further research elucidating its potential role in bone remodeling in axSpA.

\section{Conflict of Interest}

There is no conflict of interest.

\section{Acknowledgements}

This study has been supported by the Project for Conceptual Development for the institution of Ministry of Health Czech Republic - Institute of Rheumatology (number 023728), by SVV for $1^{\text {st }}$ Faculty of Medicine UK (number 260373) and grant MHCR (number: 17-33127A)

\section{References}

AMONKAR SD, BERTENSHAW GP, CHEN TH, BERGSTROM KJ, ZHAO J, SESHAIAH P, YIP P, MANSFIELD BC: Development and preliminary evaluation of a multivariate index assay for ovarian cancer. PLoS One 4: e4599, 2009. https://doi.org/10.1371/journal.pone.0004599

BUBOVA K, FOREJTOVA S, ZEGZULKOVA K, GREGOVA M, HUSAKOVA M, FILKOVA M, HORINKOVA J, GATTEROVA J, TOMCIK M, SZCZUKOVA L, PAVELKA K, SENOLT L: Cross-sectional study of patients with axial spondyloarthritis fulfilling imaging arm of ASAS classification criteria: baseline clinical characteristics and subset differences in a single-centre cohort. BMJ Open 9: e024713, 2019. https://doi.org/10.1136/bmjopen-2018-024713

DEODHAR SD: C-reactive protein: the best laboratory indicator available for monitoring disease activity. Cleve Clin J Med 56: 126-130, 1989. https://doi.org/10.3949/ccjm.56.2.126 
DINCER U, CAKAR E, KIRALP MZ, DURSUN H: Diagnosis delay in patients with ankylosing spondylitis: possible reasons and proposals for new diagnostic criteria. Clin Rheumatol 27: 457-462, 2008. https://doi.org/10.1007/s10067-007-0727-6

FOREJTOVA S, MANN H, STOLFA J, VEDRAL K, FENCLOVA I, NEMETHOVA D, PAVELKA K: Factors influencing health status and disability of patients with ankylosing spondylitis in the Czech Republic. Clin Rheumatol 27: 1005-1013, 2008. https://doi.org/10.1007/s10067-008-0845-9

GUPTA L, BHATTACHARYA S, AGGARWAL: Tenascin-C, a biomarker of disease activity in early ankylosing spondylitis. Clin Rheumatol 37: 1401-1405, 2018. https://doi.org/10.1007/s10067-017-3938-5

HASEGAWA M, HIRATA H, SUDO A, KATO K, KAWASE D, KINOSHITA N, YOSHIDA T, UCHIDA A: Tenascin-C concentration in synovial fluid correlates with radiographic progression of knee osteoarthritis. J Rheumatol 31: 2021-2016, 2004.

HASEGAWA M, NAKOSHI Y, MURAKI M, SUDO A, KINOSHITA N, YOSHIDA T, UCHIDA A: Expression of large tenascin-C splice variants in synovial fluid of patients with rheumatoid arthritis. J Orthop Res 25 : 563-568, 2007. https://doi.org/10.1002/jor.20366

JONES SD, CALIN A, STEINER A: An update on the Bath Ankylosing Spondylitis Disease Activity and Functional Indices (BASDAI, BASFI): excellent Cronbach's alpha scores. J Rheumatol 23: 407, 1996.

MAKSYMOWYCH WP: An update on biomarker discovery and use in axial spondyloarthritis. Expert Rev Mol Diagn 17: 965-974, 2017. https://doi.org/10.1080/14737159.2017.1381562

MIDWOOD K, SACRE S, PICCININI AM, INGLIS J, TREBAUL A, CHAN E, DREXLER S, SOFAT N, KASHIWAGI M, OREND G, BRENNAN F, FOXWELL B: Tenascin-C is an endogenous activator of Toll-like receptor 4 that is essential for maintaining inflammation in arthritic joint disease. Nat Med 15: 774-780, 2009. https://doi.org/10.1038/nm.1987

MIDWOOD KS, CHIQUET M, TUCKER RP, OREND G: Tenascin-C at a glance. J Cell Sci 129: 4321-4327, 2016. https://doi.org/10.1242/jes.190546

MIDWOOD KS, OREND G: The role of tenascin-C in tissue injury and tumorigenesis. J Cell Commun Signal 3 : 287-310, 2009. https://doi.org/10.1007/s12079-009-0075-1

PAGE TH, CHARLES PJ, PICCININI AM, NICOLAIDOU V, TAYLOR PC, MIDWOOD KS: Raised circulating tenascin-C in rheumatoid arthritis. Arthritis Res Ther 14: R260, 2012. https://doi.org/10.1186/ar4105

PODDUBNYY DA, RUDWALEIT M, LISTING J, BRAUN J, SIEPER J: Comparison of a high sensitivity and standard $\mathrm{C}$ reactive protein measurement in patients with ankylosing spondylitis and non-radiographic axial spondyloarthritis. Ann Rheum Dis 69: 1338-1341, 2010. https://doi.org/10.1136/ard.2009.120139

PRAJZLEROVA K, GROBELNA K, PAVELKA K, SENOLT L, FILKOVA M: An update on biomarkers in axial spondyloarthritis. Autoimmun Rev 15: 501-509, 2016. https://doi.org/10.1016/j.autrev.2016.02.002

RUDWALEIT M, BRAUN J, SIEPER J, ASSESSMENT OF SPONDYLOARTHRITIS INTERNATIONAL S: [ASAS classification criteria for axial spondyloarthritis]. Z Rheumatol 68: 591-593, 2009. https://doi.org/10.1007/s00393-009-0510-y

RUHMANN M, PICCININI AM, KONG PL, MIDWOOD KS: Endogenous activation of adaptive immunity: tenascin-C drives interleukin-17 synthesis in murine arthritic joint disease. Arthritis Rheum, 64: 2179-2190, 2012. https://doi.org/10.1002/art.34401

SATO A, AONUMA K, IMANAKA-YOSHIDA K, YOSHIDA T, ISOBE M, KAWASE D, KINOSHITA N, YAZAKI Y, HIROE M: Serum tenascin-C might be a novel predictor of left ventricular remodeling and prognosis after acute myocardial infarction. J Am Coll Cardiol 47: 2319-2325, 2006. https://doi.org/10.1016/j.jacc.2006.03.033

SHAO H, KIRKWOOD JM, WELLS A: Tenascin-C Signaling in melanoma. Cell Adh Migr 9: 125-130, 2016. https://doi.org/10.4161/19336918.2014.972781

SHUKLA A, GAUR P, AGGARWAL A: Tenascin-C levels, a toll-like receptor 4 ligand, in enthesitis-related arthritis category of juvenile idiopathic arthritis: A cross-sectional and longitudinal study. J Rheumatol 42: 891-896, 2015. https://doi.org/10.3899/jrheum.141365

SIEPER J, PODDUBNYY D: Axial spondyloarthritis. Lancet 390: 73-84, 2017. https://doi.org/10.1016/S0140$\underline{6736(16) 31591-4}$ 
SORENSEN J, HETLAND ML: Diagnostic delay in patients with rheumatoid arthritis, psoriatic arthritis and ankylosing spondylitis: results from the Danish nationwide DANBIO registry. Ann Rheum Dis 74: e12, 2015. https://doi.org/10.1136/annrheumdis-2013-204867

SPOORENBERG A, VAN DER HEIJDE D, DE KLERK E, DOUGAdOS M, DE VLAM K, MIELANTS H, VAN DER TEMPEL H, VAN DER LINDEN S: Relative value of erythrocyte sedimentation rate and C-reactive protein in assessment of disease activity in ankylosing spondylitis. J Rheumatol 26: 980-984, 1999.

TANAKA H, EL-KAREF A, KAITO M, KINOSHITA N, FUJITA N, HORIIKE S, WATANABE S, YOSHIDA T, ADACHI Y: Circulating level of large splice variants of tenascin-C is a marker of piecemeal necrosis activity in patients with chronic hepatitis C. Liver Int, 26: 311-318, 2006. https://doi.org/10.1111/j.14783231.2005.01229.x

UDALOVA IA, RUHMANN M, THOMSON SJ, MIDWOOD KS: Expression and immune function of tenascin-C. Crit Rev Immunol 31: 115-45, 2011. https://doi.org/10.1615/CritRevImmunol.v31.i2.30

VAN DER LINDEN S, VALKENBURG HA, CATS A: Evaluation of diagnostic criteria for ankylosing spondylitis. A proposal for modification of the New York criteria. Arthritis Rheum 27: 361-368, 1984. https://doi.org/10.1002/art.1780270401

ZÁVADA J, UHER M, SVOBODOVÁ R, OLEJÁROVÁ M, HUŠÁKOVÁ M, CIFERSKÁ H, HULEJOVÁ H, TOMČÍK M, ŠENOLT L, VENCOVSKÝ J: Serum tenascin-C discriminates patients with active SLE from inactive patients and healthy controls and predicts the need to escalate. Arthritis Res Ther 17: 341, 2015. https://doi.org/10.1186/s13075-015-0862-4 